Gut, 1977, 18, 57-63

\title{
Basal gastric secretion: reproducibility and relationship with duodenal ulceration
}

\author{
R. G. FABER AND M. HOBSLEY \\ From the Department of Surgical Studies, The Middlesex Hospital and Medical School, London
}

SUMMARY Basal gastric secretion was examined in control subjects, patients with duodenal ulcer, and patients after vagotomy with or without a drainage procedure, not only in terms of conventional indices of secretion-volume, titratable acidity, and acid output-but also in terms of the volume corrected for pyloric losses and duodenal reflux $\left(\mathrm{V}_{\mathbf{G}}\right)$. In all groups, secretion was less in the second than in the first half-hour of a one-hour basal collection. Basal secretion was examined on more than one occasion in non-operated subjects and patients after vagotomy with or without a drainage procedure. In both groups extreme variability in secretion was found from one study to the next, and the variability was the same whether secretion was expressed in terms of conventional indices or $V_{G}$. It is concluded that such variability is physiological rather than due to experimental errors. Basal secretion was found on average to be greater in duodenal ulcer patients than in control subjects, and, after vagotomy, to be greater in patients with recurrent ulcer than in asymptomatic patients. However, despite all the corrections made, the overlap in the results from the different groups was so great that basal secretion could not be ascribed an aetiological role in the majority of patients with duodenal ulcer.

The role of basal gastric secretion in the pathogenesis of duodenal ulcer, and of recurrent ulcer after vagotomy, has not been satisfactorily defined. Most, but not all, authors agree that on average basal secretion is greater, firstly, in patients with duodenal ulcer than in normal controls, and, secondly, in patients with recurrent ulcer than in asymptomatic patients after vagotomy, but, equally, it is agreed that there is considerable overlap between the different groups in terms of the individual subject. Despite this, the impression remains that basal secretion is an aetiological factor in the development of duodenal ulcer if only it could be accurately determined.

There are three potential errors in the estimation of basal gastric secretion. Firstly, as basal secretion is small in volume and low in titratable acidity, it is peculiarly susceptible to the effects of pyloric losses and duodenogastric reflux. Secondly, gastric secretion might take a long time to settle down to a truly basal state after the subject swallows the nasogastric tube. Thirdly, basal secretion, at least as measured by routine techniques, is known to be variable both during a prolonged period of col-

Received for publication 16 August 1976 lection (Gillespie et al., 1972), and also if the measurement is repeated on a subsequent occasion (Baron, 1963). In the present study we have used techniques previously described (Hobsley, 1974) to quantify the first of these errors, pyloric losses and duodenogastric reflux. In the first part of the investigation we have examined the second and third potential errors, by measuring basal secretion over consecutive half-hour periods of a 60 or 90 minute collection, and on two different occasions in the same individual. These results have been applied, in the second part of the study, to an attempt to answer two questions: (1) is an increased basal acid secretion an aetiological factor in the development of duodenal ulcer? (2) does vagotomy cure duodenal ulceration by reducing basal secretion to a sufficiently low level?

\section{Methods}

Each subject fasted and abstained from all medication known to affect gastric secretion from midnight. From 9 a.m. the subject lay semirecumbent on a couch, a specially prepared two-lumen tube (Thomson et al., 1973) was passed, and its correct position in the stomach checked by the water 
recovery test (Hassan and Hobsley, 1970). In the majority of studies a syringe containing phenol red (Hunt, 1954) mounted on a Palmer infusion pump was immediately connected to the inner lumen of the nasogastric tube; the phenol red was then infused into the stomach at the rate of $10.4 \mathrm{ml} / \mathrm{h}$. Gastric juice was collected for 10 minutes and discarded before the beginning of the definitive basal collection. Collection of gastric juice was by continuous aspiration and samples were removed at 10-minute intervals. In these patients data were available for the whole basal period of at least 60 minutes, and in the case of eight patients for 90 minutes, and these are the data examined in part 1 of the Results section. In a minority of studies the nasogastric tube was connected to the aspirating pump immediately after the completion of the water recovery test. The one-hour basal collection was started before the phenol red syringe was connected to the inner lumen, so that data for the first halfhour of the basal collection were disregarded. However, by the second half-hour, adequate phenol red mixing had occurred, and therefore $V_{G}$ could be calculated, and the addition of these data to those of the subjects in part 1 results in the larger numbers examined in part 2.

CALCULATIONS AND STATISTICAL METHODS Each sample of gastric juice was handled and analysed exactly as we have previously described (Faber et al., 1974; Faber et al., 1975); the observed volume $V_{\text {obs }}(\mathrm{ml} / 10 \mathrm{~min})$, titratable acidity $\left(\left[\mathrm{H}^{+}\right] \mathrm{mmol} / \mathrm{l}\right)$, basal acid output (BAO $\mathrm{mmol} / 10 \mathrm{~min}$ ) and the volume of gastric juice corrected for pyloric losses and duodenal reflux $\left(\mathrm{V}_{\mathrm{G}} \mathrm{ml} / 10 \mathrm{~min}\right)$ were calculated for each sample. For the first, second, and, where appropriate, the third basal half-hours of each subject the secretion was expressed as $V_{\text {obs }} \mathrm{ml} / \mathrm{h}$ (the sum of the three 10 minute samples $\times 2$ ), BAO $\mathrm{mmol} / \mathrm{h}$ (the sum of the products of $\mathrm{V}_{\text {obs }} \times\left[\mathrm{H}^{+}\right] / 1000$ of each 10 minute sample $\times 2$ ), $\left[\mathrm{H}^{+}\right] \mathrm{mmol} / 1\left(\mathrm{BAO} \times 1000 / \mathrm{V}_{\mathrm{obs}}\right)$, and $\mathrm{V}_{\mathrm{G}} \mathrm{ml} / \mathrm{h}$ (the sum of the three 10 minute samples $\times 2$ ). Unlike maximal gastric secretion (Baron, 1964; Hobsley et al., 1975), no correlation between basal gastric secretion and stature could be found, so no correction for stature could be made.

Statistical examination of the results of this study have been made in several ways. Firstly, comparison of secretion in the same individual examined on different occasions has been made using the paired $t$ test. Secondly, comparison of the mean secretion in different groups has been made using the unpaired $t$ test. Thirdly, the $95 \%$ tolerance limits of secretion of each group have been determined by calculating two standard deviations around the mean. All these statistical tests require that the data be normally distributed. In order to test the distributions, the secretion data of the normal controls, patients with duodenal ulcer, and asymptomatic post-vagotomy patients (examined in the Results section, part 2 and depicted in Figs. 1 and 2) were studied.

The data, expressed as $V_{G}$ and $\mathrm{BAO}$, were examined in two ways, firstly, assuming a normal distribution, and, secondly, after logarithmic transformation. In terms of $V_{G}$ the transformation was simply made by taking the natural logarithm of each value; in terms of acid output, in order to eliminate zeros and figures less than unity, it was necessary to add one to each value before taking the natural logarithm. The actual distributions were compared with the theoretically normal distributions by the $\chi^{2}$ test using the method described by Cooper (1969). The details are summarised in Table 1 . In terms of acid output it can clearly be seen that the distribution of the raw data was significantly different from normal, while after logarithmic transformation such differences disappeared. In terms of $V_{G}$ only the data from patients with duodenal ulcer differed from normality, but after logarithmic transformation none of the groups differed from normality. Furthermore, the numbers of points from each group with a value greater or lesser than the mean value of that group are also shown in Table 1 , and it can be seen that for all three groups the mean and median are closer after logarithmic transformation. Therefore, all data were transformed to the natural logarithm.

In the study of secretion in the same individual examined on different occasions (Results section, part 1B) the difference between the first and second test was either positive or negative, and the mean difference of each group was insignificantly different from zero. The distribution of these differences around zero was not significantly different from normal, so the $95 \%$ tolerance limits were calculated as two standard deviations of the individual differences. However, in examining the change of secretion from before to after operation (Results section, part 2B, and Fig. 3) satisfactory transformation of data to normality was not possible. For this reason a non-parametric test, the Mann-Whitney U-test, was used.

\section{Results $^{1}$}

PART 1: STABILITY OF BASAL SECRETION

\section{A Stability during one collection}

One hour basal collections were carried out in 55

${ }^{1}$ Full data are available on request to the authors. 


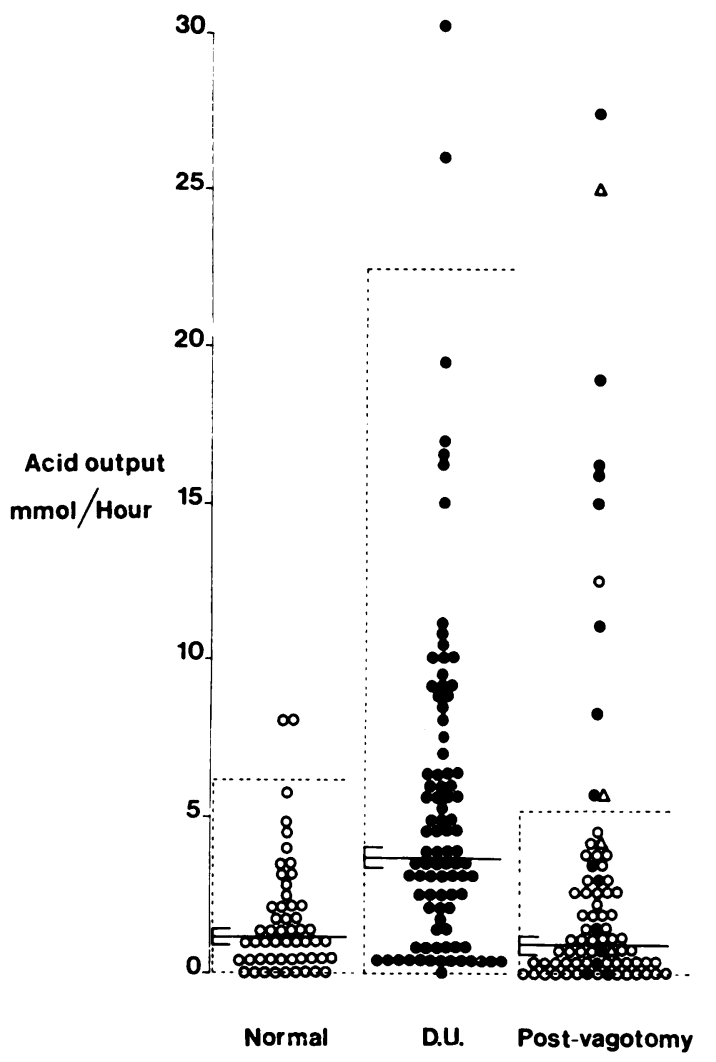

Fig. 1 Basal secretion, expressed as acid output ( $\mathrm{mmol} / \mathrm{h}$ ) in normal controls and patients with duodenal ulcer before and after vagotomy. Post-vagotomy group: patients with recurrent ulcer (O), patients with recurrent symptoms $(\triangle)$ and patients with no symptoms $(O)$. Means, standard errors of the means, and $95 \%$ tolerance limits of the ranges were calculated after logarithmic transformation; these values for the post-vagotomy group were calculated from the data on the asymptomatic subjects, and the data from the patients with recurrent ulcer or recurrent symptoms were not included.

control subjects, 65 patients with duodenal ulcer, and 57 patients who had been treated for duodenal ulcer by vagotomy with or without a drainage procedure. The first and second half-hours of the basal secretion in each group were compared, and the details are tabulated in Table 2 . In all three groups secretion was significantly less in the second half-hour in terms of $\mathbf{V}_{\text {obs }}$ and $V_{G}$, and it was only in the duodenal ulcer group that this difference could not be shown in terms of BAO. In the eight subjects studied for 90 minutes, it was only in terms of $V_{G}$ that secretion could be shown to be less in the second compared with the first half-hour

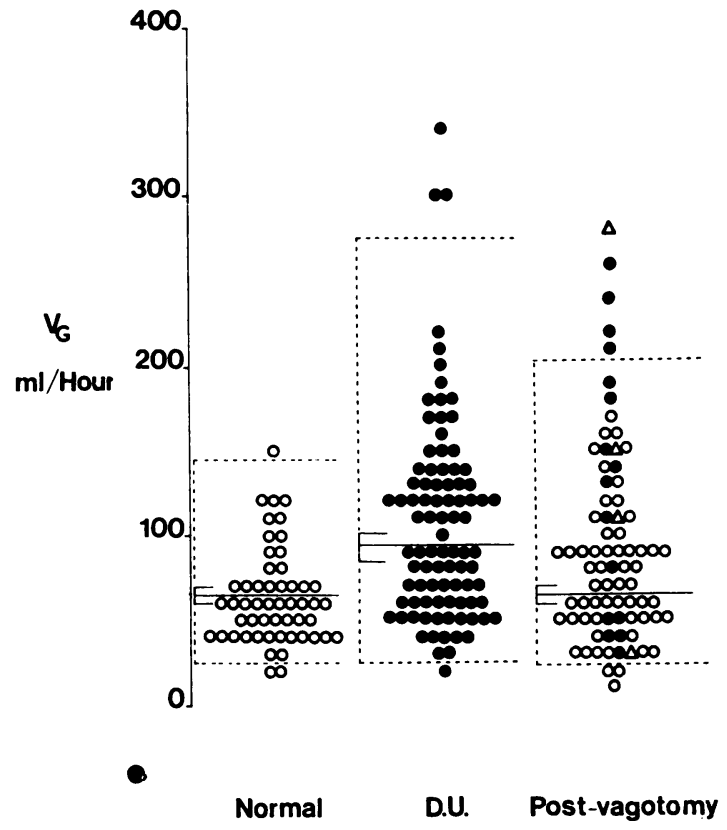

Fig. 2 Basal secretion expressed as $V_{G}(\mathrm{ml} / \mathrm{h})$ in normal controls and patients with duodenal ulcer before and after vagotomy. Post-vagotomy group: patients with recurrent ulcer $(\bigcirc)$, patients with recurrent symptoms $(\triangle)$, and patients with no symptoms $(\bigcirc)$. Means, standard errors of the means, and $95 \%$ tolerance limits of the ranges were calculated after logarithmic transformation; these values for the post-vagotomy group were calculated from the data on the asymptomatic subjects, and the data from the patients with recurrent ulcer or recurrent symptoms were not included.

$(t=2.890, \mathrm{P}<0.025)$. In terms of no index of secretion could a difference between the second and third half-hours be shown $\left(\mathrm{V}_{\mathrm{G}} t=0.713 ; \mathrm{BAO}\right.$ $t=0.833$ ).

In view of these findings, all comparisons of basal secretion were made using only data obtained during the second half-hour of the basal collection.

\section{$B$ Reproducibility of repeated collections}

The second half-hour of basal secretion of all subjects who had a one-hour basal collection on two separate occasions was examined. Data were available for 24 patients who had not had an operation and for 38 patients after vagotomy for duodenal ulcer. In both groups the differences between the first and second studies were quantified. The $95 \%$ tolerance limits of the difference between the two tests were calculated and full details are shown in Table 3. For both groups these limits were approximately $\pm 100 \mathrm{ml} / \mathrm{h}$ in terms of $V_{o b s}$ and $V_{G}$, and 
Table 1 Comparison between actual distributions and theoretically normal distributions

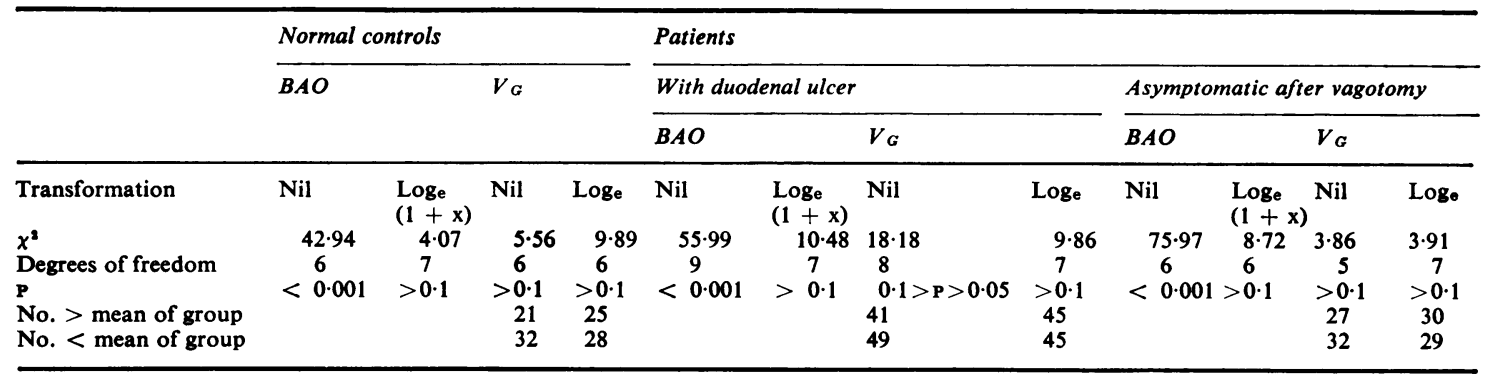

$\pm 45 \mathrm{mmol} / \mathrm{l}$ in terms of $\left[\mathrm{H}^{+}\right]$. In terms of BAO these limits were $\pm 9 \mathrm{mmol} / \mathrm{h}$ for the preoperative patients and $\pm 7 \mathrm{mmol} / \mathrm{h}$ for the post-vagotomy patients. It can be seen that the variability of repeated measurements in each subject greatly exceeded the tiny but significant decrease in the post-vagotomy group demonstrated in terms of $\left[\mathrm{H}^{+}\right]$and BAO. In other words, the reproducibility of repeated collections was very poor.

\section{PART 2: BASAL SECRETION AND DUODENAL} ULCERATION

\section{A Comparison between different groups}

Full data of the second half-hour of one hour basa collections were available in 53 normal controls, 90 patients with duodenal ulcer, and 79 patients after vagotomy for duodenal ulcer, of whom 59 were asymptomatic, four had recurrent symptoms,

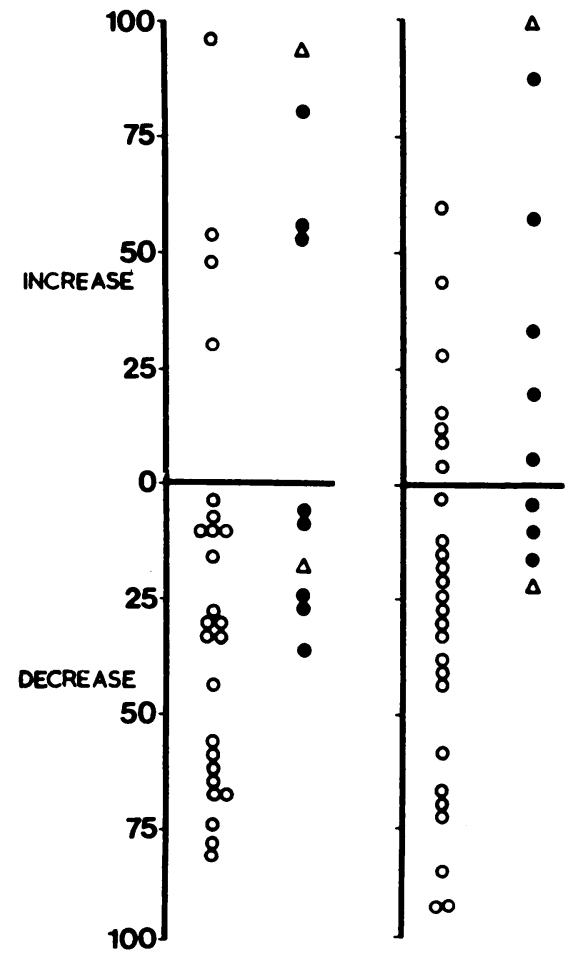

N.S.

Voes

$\mathrm{ml} /$ hour

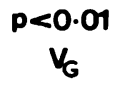

ml hour

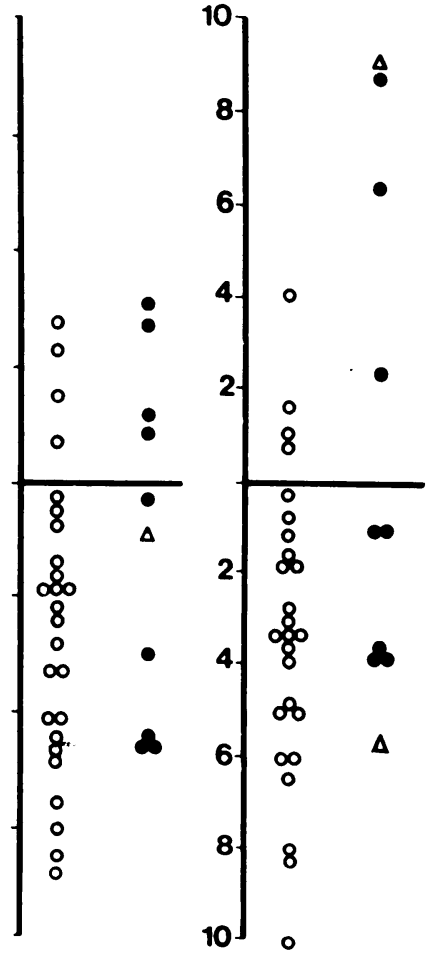

Fig. 3 The change in basal secretion in patients with duodenal ulcer having studies before and after vagotomy. Secretion is expressed as $V_{o b s}(\mathrm{ml} / \mathrm{h})$, $V_{G}(\mathrm{ml} / \mathrm{h})$, titratable acidity (mmol/l), and acid output $(\mathrm{mmol} / \mathrm{h})$. Patients with recurrent ulcer (๑), patients with recurrent symptoms $(\triangle)$, patients with no symptoms (O). Differences between the two groups were tested by the Mann-Whitney U-test, and only in terms of $V_{G}$ was significant difference found. 
Table 2 Comparison of secretion during first (1) and second (2) half-hours of one-hour basal collection in terms of four indices of secretion

\begin{tabular}{|c|c|c|c|c|c|}
\hline & & \multicolumn{4}{|c|}{ Index of secretion } \\
\hline & & $V_{\text {obs }}(m l / h)$ & {$\left[\mathrm{H}^{+}\right](\mathrm{mmol} / \mathrm{l})$} & $B A O(\mathrm{mmol} / \mathrm{h})$ & $V_{G}(m l / h)$ \\
\hline Controls & $\begin{array}{l}\text { Comparison } \\
t \\
\mathrm{P}\end{array}$ & $\begin{array}{r}1>2 \\
4.387 \\
<0.001\end{array}$ & $\begin{array}{l}\text { ND } \\
0.711 \\
\text { NS }\end{array}$ & $\begin{array}{l}1>2 \\
2.102 \\
<0.05\end{array}$ & $\begin{array}{l}1>2 \\
7.537 \\
<0.001\end{array}$ \\
\hline $\begin{array}{l}\text { Patient with } \\
\text { duodenal ulcer }\end{array}$ & $\begin{array}{l}\text { Comparison } \\
t \\
\mathbf{P}\end{array}$ & $\begin{array}{l}1>2 \\
2.739 \\
<0.01\end{array}$ & $\begin{array}{l}\text { ND } \\
0.462 \\
\text { NS }\end{array}$ & $\begin{array}{l}\text { ND } \\
1.639 \\
\text { NS }\end{array}$ & $\begin{array}{c}1>2 \\
7.242 \\
<0.001\end{array}$ \\
\hline $\begin{array}{l}\text { Post-vagotomy } \\
\text { patients }\end{array}$ & $\begin{array}{l}\text { Comparison } \\
t \\
\mathrm{P}\end{array}$ & $\begin{array}{r}1>2 \\
4.914 \\
<0.001\end{array}$ & $\begin{array}{l}\text { ND } \\
0.921 \\
\text { NS }\end{array}$ & $\begin{array}{l}1>2 \\
2.863 \\
<0.01\end{array}$ & $\begin{array}{l}1>2 \\
4.353 \\
<0.001\end{array}$ \\
\hline
\end{tabular}

Differences were tested by the paired $t$ test after logarithmic transformation of the data.

ND: no difference NS: not significant

Table 3 Comparison of secretion during the second half-hours of one hour basal collections in patients having two separate studies

\begin{tabular}{|c|c|c|c|c|}
\hline & \multicolumn{4}{|c|}{ Index of secretion } \\
\hline & $V_{o b s}(m l / h)$ & {$\left[\mathrm{H}^{+}\right](\mathrm{mmol} / \mathrm{l})$} & $B A O(\mathrm{mmol} / \mathrm{h})$ & $V_{G}(m l / h)$ \\
\hline \multicolumn{5}{|l|}{ Preoperative patients (24) } \\
\hline Comparison of 1 st and 2 nd studies & ND & ND & ND & ND \\
\hline$t$ & 0.733 & 0.378 & 0.914 & $0 \cdot 281$ \\
\hline $\mathbf{P}$ & NS & NS & NS & NS \\
\hline Mean difference between studies & & $1 \cdot 4$ & 0.79 & $3 \cdot 2$ \\
\hline Standard deviation & $\pm 50 \cdot 5$ & $\pm 21 \cdot 2$ & $\pm 4 \cdot 64$ & \pm 53.8 \\
\hline $95 \%$ Tolerance limits & $\pm 101 \cdot 2$ & $\pm 42 \cdot 2$ & $\pm 9 \cdot 28$ & \pm 107.6 \\
\hline \multicolumn{5}{|l|}{ Post-vagotomy patients (38) } \\
\hline Comparison of 1 st and 2 nd studies & ND & $1>2$ & $1>2$ & ND \\
\hline$t$ & 1.946 & 3.023 & 2.689 & 1.640 \\
\hline $\mathbf{P}$ & & $<0.01$ & $<0.01$ & NS \\
\hline Mean difference between studies & -15.8 & $-8 \cdot 1$ & -0.80 & -20.9 \\
\hline Standard deviation & $\pm \mathbf{5 3 . 0}$ & $\pm 23 \cdot 0$ & $\pm 3 \cdot 64$ & $\pm \mathbf{4 6 . 9}$ \\
\hline $95 \%$ Tolerance limits & \pm 106.0 & $\pm 46 \cdot 0$ & $\pm 7 \cdot 28$ & \pm 93.8 \\
\hline
\end{tabular}

The differences were tested by the paired $t$ test after logarithmic transformation. The mean differences and standard deviation of the differences were calculated from the actual individual differences without transformation of the data.

Table 4 Duodenal ulcer patients with basal secretion in excess of upper $95 \%$ tolerance limits of normal group

\begin{tabular}{llcll}
\hline \multicolumn{5}{c}{ Index of secretion } \\
\cline { 2 - 5 }$V_{\text {obs }}$ & $\begin{array}{l}\text { Titratable } \\
\text { acidity }\end{array}$ & $\begin{array}{l}\text { Acid } \\
\text { output }\end{array}$ & $V_{G}$ \\
\hline $\begin{array}{l}\text { Value of } \\
\text { upper } 95 \%\end{array}$ & $131(\mathrm{ml} / \mathrm{h})$ & $\begin{array}{l}>>150 \\
(\mathrm{mmol} / \mathrm{l})\end{array}$ & $\begin{array}{c}6 \cdot 14 \\
(\mathrm{mmol} / \mathrm{h})\end{array}$ & $143(\mathrm{ml} / \mathrm{h})$ \\
$\begin{array}{l}\text { limit of } \\
\text { normal } \\
\text { group }\end{array}$ & 15 & 0 & 26 & 17 \\
$\begin{array}{l}\text { Number of } \\
\text { patients } \\
\text { Percentage } \\
\text { of DU } \\
\text { patients }\end{array}$ & 17 & 0 & 29 & 19 \\
\hline
\end{tabular}

Comparison of the 26 out of 90 DU patients in terms of acid output and of the 17 out of 90 in terms of $V_{G}$ with secretion in excess of the normal group. $x^{2}=1 \cdot 96, \mathrm{P}>0 \cdot 1$.

and 16 had proven recurrent ulcers. Figures 1 and 2 show the basal secretion of each group in terms of $B A O$ and $V_{G}$. Included in each Figure are the means, standard errors, and $95 \%$ tolerance limits; although all the post-vagotomy patients are plotted together, the means, standard errors, and ranges refer only to the asymptomatic subjects. In Table 4 are listed the values, in terms of $\mathrm{V}_{\text {obs }}$ and $\left[\mathrm{H}^{+}\right]$as well as $\mathrm{BAO}$ and $V_{G}$, of the upper $95 \%$ tolerance limits of basal secretion in the normal group, together with the number of individual duodenal ulcer patients with basal secretion in excess of these limits. By all indices, less than $30 \%$ of duodenal ulcer patients exceeded these limits. Likewise in Table 5 are listed the upper $95 \%$ tolerance limits of basal secretion of the asymptomatic post-vagotomy group together with the number of patients with recurrent ulcer with basal secretion in excess of these limits. Between one quarter and one half of these could be characterised by these limits.

The groups were compared using the unpaired $t$ test, and a summary of the $t$ values and significances is given in Table 6. By all indices of secretion, basal secretion in the duodenal ulcer group was significantly greater than in the normal group and in the asymptomatic post-vagotomy group. Also, by 
Table 5 Patients with recurrent ulcer after vagotomy with basal secretion in excess of upper $95 \%$ tolerance limits of post-vagotomy patients without symptoms

\begin{tabular}{lllll}
\hline \multicolumn{5}{c}{ Index of secretion } \\
\cline { 2 - 5 } & $V_{\text {obs }}$ & $\begin{array}{l}\text { Titratable } \\
\text { acidity }\end{array}$ & $\begin{array}{l}\text { Acid } \\
\text { output }\end{array}$ & $V_{G}$ \\
\hline $\begin{array}{l}\text { Value of } \\
\text { upper } 95 \%\end{array}$ & $181(\mathrm{ml} / \mathrm{h})$ & $\begin{array}{l}>>150 \\
(\mathrm{mmol} / \mathrm{l})\end{array}$ & $\begin{array}{c}5 \cdot 27 \\
(\mathrm{mmol} / \mathrm{h})\end{array}$ & $202(\mathrm{ml} / \mathrm{h})$ \\
$\begin{array}{l}\text { limit of } \\
\text { asympto- } \\
\text { matic post- } \\
\text { vagotomy } \\
\text { group }\end{array}$ & & & & \\
$\begin{array}{l}\text { Patients with } \\
\text { ulcer (no.) } \\
\%\end{array}$ & 4 & 0 & 8 & 4 \\
\hline
\end{tabular}

Comparison of the eight out of 16 patients with recurrent ulcer in terms of acid output and of the four out of 16 in terms of $V_{G}$ with secretion in excess of the asymptomatic group. $P=0 \cdot 14$, Fisher's exact test.

all indices basal secretion was greater in the recurrent ulcer group than in the asymptomatic postvagotomy group. However, secretion was not greater in the normal controls than in the asymptomatic post-vagotomy patients, except in terms of titratable acidity.

\section{$B$ Comparison of preoperative and postoperative secretion in the same subject}

Basal secretion was examined in 22 patients having studies before and after vagotomy. Eighteen patients were studied on three occasions, either two before and one after operation or vice versa, giving 36 paired collections for comparison of changes consequent upon vagotomy. The changes in secretion in terms of $\mathrm{V}_{\mathrm{obs}},\left[\mathrm{H}^{+}\right], \mathrm{BAO}$ and $\mathrm{V}_{\mathrm{G}}$ are plotted in Fig. 3 comparing the asymptomatic subjects with the group including patients with recurrent ulcer and recurrent symptoms. Only in terms of $V_{G}$ was there a significant difference between the two groups. However, there was such overlap between the two groups by all indices of secretion that change of basal secretion from before to after vagotomy could not predict recurrent ulceration in the individual.

\section{Discussion}

There are two important differences in the methods used in this investigation compared with previous reports. Firstly, statistical methods were used (see the section on Calculations and statistical methods) which either corrected data to a normal distribution or were distribution-free. Secondly, we have been able to calculate $\mathrm{V}_{\mathrm{G}}$, the volume of gastric juice corrected for pyloric losses and duodenal reflux. There is evidence in these results to confirm our opinion (Hobsley, 1974; Faber et al., 1975) that $\mathbf{V}_{\mathbf{G}}$ is the most accurate index of gastric secretion. For example, the reduction in secretion during the second basal half-hour compared with the first, an effect which had been clearly proven in the larger groups with several indices, could be demonstrated in a small group of eight subjects only by using $\mathrm{V}_{\mathrm{G}}$; the other indices all failed to demonstrate this difference. Again, $V_{G}$ was the only index of secretion to demonstrate that the group of patients after vagotomy who had no symptoms of recurrent ulceration had had a greater reduction in basal secretion than the group of patients with recurrent symptoms or recurrent ulceration.

The results in the first part of this investigation show clearly that basal secretion is greater during the first half-hour than during the second half-hour of a one hour collection, and these results hold good, not only for observed (uncorrected) basal secretion, but also after the application of corrections for pyloric losses and duodenal reflux. A corollary of this finding is that studies in basal secretion should not start until half an hour after the subject has swallowed the nasogastric tube; the gastric contents should be aspirated and discarded during the intervening period. There does not seem to be any point in waiting longer than 30 minutes, because we have been unable to demonstrate any significant change in secretion from the second to the third half-hour of a 90-minute collection. Levin and his colleagues (Levin et al., 1948; Kirsner et al., 1956) likewise reported a greater fall in secretion during

Table 6 Significance of differences between basal secretion in different groups

\begin{tabular}{|c|c|c|c|c|c|}
\hline & & Vobs & {$\left[\mathrm{H}^{+}\right]$} & Acid output & $V_{G}$ \\
\hline $\begin{array}{l}\text { Normal vs. } \\
\text { DU } \\
\text { Normal vs. post-vagotomy } \\
\text { asymptomatic } \\
\text { DU vs. post-vagotomy asymptomatic } \\
\text { Post-vagotomy asymptomatic vs. } \\
\text { recurrent ulcer }\end{array}$ & $\begin{array}{l}t \\
\mathbf{P} \\
t \\
\mathbf{P} \\
t \\
\mathbf{P} \\
t \\
\mathrm{P}\end{array}$ & $\begin{array}{r}6.237 \\
<0.001 \\
1.248 \\
\text { NS } \\
4.700 \\
<0.001 \\
2.202 \\
<0.05\end{array}$ & $\begin{aligned} & 3.402 \\
&<0.005 \\
& 2.141 \\
& P<0.05 \\
& 5.923 \\
&<0.001 \\
& 2.036 \\
&<0.05\end{aligned}$ & $\begin{array}{r}5.801 \\
<0.001 \\
1.501 \\
\text { NS } \\
7.361 \\
<0.001 \\
4.581 \\
<0.001\end{array}$ & $\begin{array}{r}4.802 \\
<0.001 \\
0.411 \\
\text { NS } \\
3.794 \\
<0.001 \\
2.810 \\
<0.01\end{array}$ \\
\hline
\end{tabular}

Except where shown (NS), DU > Normal. DU > Asymptomatic post-vagotomy. RU > Asymptomatic post-vagotomy. Normal > Asymptomatic post-vagotomy. 
the first half-hour of basal collection than in subsequent periods.

Turning now to the second part of the study, do our results support the Dragstedt hypothesis of the aetiology of duodenal ulceration? He summarised his theory by stating (Dragstedt, 1956): 'I believe that duodenal ulcers are due to a hypersecretion of gastric juice in the empty stomach dependent upon excessive and abnormal secretory impulses in the vagus nerves'. With regard to 'basal hyper-secretion', it is true that we have shown (Table 6) that the mean secretion of the duodenal ulcer group was significantly greater than that of the normal controls. However, in terms of the individual subject, only between $20 \%$ and $30 \%$ secreted more acid than the normal population (Table 4). With regard to 'excessive and abnormal secretory impulses in the vagus nerves' it would be expected that vagotomy should abolish these impulses, and this is the rationale for performing the operation. We have examined the effect of vagotomy on basal gastric secretion in two ways. Firstly, the extent by which operation reduced secretion in each individual patient was compared with the efficacy of the operation in preventing recurrence in that patient. In terms of $\mathbf{V}_{\mathbf{G}}$ it could be demonstrated that the reduction in secretion in asymptomatic patients was greater than that of patients with recurrent ulcer. However, there was considerable overlap between the two groups and a number of asymptomatic patients showed either little decrease or an actual increase in secretion after operation (Fig. 3). Secondly, in comparing the postoperative basal secretion of patients with recurrent ulcers with that of patients with no symptoms, only between one-quarter and one-half of the former-that is, with a proven inadequate vagotomy-had secretion in excess of that of the latter (Table 5).

These results give no support to the Dragstedt hypothesis. The difference between Dragstedt's and our results cannot be attributed to the fact that he usually measured 12-hour nocturnal secretion; it has been shown (Levin et al., 1951) that a one-hour basal collection is representative of the nocturnal collection. The best that can be said for Dragstedt's hypothesis is that, in terms of our present ability to measure gastric secretion, increased vagal drive can only be an aetiological factor in duodenal ulceration in a minority (one-fifth to one-quarter) of patients. This corresponds with our previous finding (Hobsley et al., 1975) that excess gastric secretion when maximally stimulated can only be an aetiological factor in about $25 \%$ of patients with duodenal ulceration. It is still possible, however, that true differences between groups are being masked by the extreme variability of basal secretion. The lack of reproducibility of repeated measurements in the same individual on different occasions, even when observations were confined to the second half-hour and secretion was expressed in terms of $V_{G}$, may be an expression of an inherent instability in basal secretion; it is however possible that the variable factor is swallowed saliva, an error for which we can make no allowance.

We would like to thank Mr Peter Whitfield for statistical and technical assistance, and our colleagues who performed a number of the secretion studies.

\section{References}

Baron, J. H. (1963). Studies of basal and peak acid output with an augmented histamine test. Gut, 4, 136-144.

Baron, J. H. (1964). Peptic ulcer, gastric secretion and body build. Gut, 5, 83-85.

Cooper, B. E. (1969). Statistics for Experimentalists, pp.7881. Pergamon Press: Oxford.

Dragstedt, L. R. (1956). Excerpta Medical Section IX: Surgery vol. 10. Quoted by Allen, J. G. in The Physiology and Treatment of Peptic Ulcer. p. 231. University of Chicago Press: Chicago.

Faber, R. G., Russell, R. C. G., Parkin, J. V., Whitfield, P., and Hobsley, M. (1975). The predictive accuracy of the post-vagotomy insulin test. Gut, 16, 337-342.

Faber, R. G., Russell, R. C. G., Royston, C. M. S., Whitfield, P., and Hobsley, M. (1974). Duodenal reflux during insulin-stimulated secretion. Gut, 15, 880-884.

Gillespie, G., Elder, J. B., Smith, I. S., Kennedy, F., Gillespie, I. E., Kay, A. W., and Campbell, E. H. G. (1972). Analysis of basal acid secretion and its relation to the insulin response in normal and duodenal ulcer subjects. Gastroenterology, 62, 903-911.

Hassan, M. A., and Hobsley, M. (1970). Positioning of subject and naso-gastric tube during a gastric secretion study. British Medical Journal, 1, 458-460.

Hobsley, M. (1974). Pyloric reflux: a modification of the two component hypothesis of gastric secretion. Clinical Science and Molecular Medicine, 47, 131-141.

Hobsley, M., Whitfield, P., Faber, R. G., and Parkin, J. V. (1975). Hypersecretion and length of history in duodenal ulceration. Lancet, 2, 101-104.

Hunt, J. N. (1954). The inhibitory action of sucrose on gastric digestive activity in patients with peptic ulcer. Guy's Hospital Report, 103, 161-173.

Kirsner, J. B., Bock, D., Palmer, W. L., Levin, E., and Ford, H. (1956). Variations in basal gastric secretion in man and the evaluation of gastric secretory stimulants. Gastroenterology, 30, 779-789.

Levin, E. Kirsner, J. B., and Palmer, W. L. (1951). A simple measure of gastric secretion in man: comparison of one hour basal secretion, histamine secretion and 12 hour nocturnal gastric secretion. Gastroenterology, 19, 88-98.

Levin, E., Kirsner, J. B., Palmer, W. L., and Butler, C. (1948). The variability and periodicity of the nocturnal gastric secretion in normal individuals. Gastroenterology, 10, 939-951.

Thomson, J. P. S., Russell, R. C. G., and Hobsley, M. (1973). Double lumen tube for gastric secretion studies. British Medical Journal, 3, 175. 